\title{
Julien Roumette, Le sublime évanescent: la tentation de l'émotion esthétique dans les romans de Perec
}

\section{Elisa Bricco}

\section{(2) OpenEdition}

1 Journals

\section{Edizione digitale}

URL: http://journals.openedition.org/studifrancesi/33706

DOI: 10.4000/studifrancesi.33706

ISSN: 2421-5856

\section{Editore}

Rosenberg \& Sellier

\section{Edizione cartacea}

Data di pubblicazione: 1 décembre 2005

Paginazione: 679

ISSN: 0039-2944

\section{Notizia bibliografica digitale}

Elisa Bricco, «Julien Roumette, Le sublime évanescent: la tentation de l'émotion esthétique dans les romans de Perec», Studi Francesi [Online], 147 (XLX | III) | 2005, online dal 30 novembre 2015, consultato il 18 avril 2021. URL: http://journals.openedition.org/studifrancesi/33706 ; DOI: https:// doi.org/10.4000/studifrancesi.33706

Questo documento è stato generato automaticamente il 18 avril 2021.

\section{(c) $(1) \odot$}

Studi Francesi è distribuita con Licenza Creative Commons Attribuzione - Non commerciale - Non opere derivate 4.0 Internazionale. 


\title{
Julien Roumette, Le sublime évanescent: la tentation de l'émotion esthétique dans les romans de Perec
}

\author{
Elisa Bricco
}

\section{NOTIZIA}

JULIEN ROUMETTE, Le sublime évanescent: la tentation de l'émotion esthétique dans les romans de Perec, «Littérature», 135, 2004, pp. 41-70.

1 Come descrive il titolo di questo interessante articolo, l'attrazione per il sublime, inteso come sentimento estetico, che costituisce una ricerca e una pulsione nell'opera di Perec, è ricercato in due romanzi che costituiscono l'inizio e la fine del percorso della scrittore: Les Choses e La Vie mode d'emploi.

2 L'A. traccia un percorso che prevede inizialmente la ricerca del sublime in Perec alla luce di Flaubert, o meglio: a partire da un parallelo con la pratica dell'ironia flaubertiana nei confronti del romanticismo più sentimentale, si mostra in quale maniera lo scrittore di Les Choses riesca a distruggere ogni tentazione di sublime. Tuttavia Perec non utilizza solo l'ironia che copre con un velo derisorio gli oggetti, i cliché, gli stereotipi, ma crea anche personaggi che non riescono a realizzare quasi nessuna azione importante, che sono totalmente estranei a qualsiasi idea di eccellenza e che rimangono addirittura insensibili dinanzi agli spettacoli della natura che generalmente suscitano l'entusiasmo dello spettatore. In definitiva, lo scrittore crea delle figure di persone incapaci di provare emozioni.

3 In La Vie mode d'emploi la prospettiva è diversa: l'approccio con il sublime è veicolato dalla percezione del sentimento estetico, e si incentra sull'analisi dell'intreccio principale del romanzo, quello che vede i due protagonisti, Percival Bartlebooth e Serge Valène, misurarsi con la pittura. L'A. si interroga sulle capacità della ricerca artistica di permettere ai protagonisti di elevarsi al di sopra delle contingenza e della fredda 
materialità alla quale aderivano i personaggi del romanzo precedente, arrivando alla conclusione che, in maniera diversa secondo il personaggio, Perec nega comunque la possibilità di raggiungere $o$ addirittura postulare il sublime.

4 Dinanzi a questa tentazione nihilistica però, l'A. rintraccia un piccolo barlume di speranza, rappresentato dalla fede dello scrittore nell'opera d'arte che, pur se incompiuta, porta in sé la possibilità, peraltro solamente ideale, di rappresentare il passato e dunque di «suspendre le temps» (p. 69). 